\title{
Influence of block freeze concentration and evaporation on physicochemical properties, bioactive compounds and antioxidant activity in blueberry juice
}

\author{
Nidia CASAS-FORERO ${ }^{1}$, Patricio ORELLANA-PALMA², Guillermo PETZOLD ${ }^{1 *}$
}

\begin{abstract}
This study investigated the impacts of centrifugal block freeze concentration (CBFC) and evaporation processes on physicochemical properties, bioactive compounds and antioxidant activity applied to fresh blueberry juice. After three concentration cycles, the solutes were approximately 3.6 times to the initial condition $\left(12^{\circ} \mathrm{Brix}\right)$ and the final color $\left(\Delta \mathrm{E}^{\star}>4.7\right)$ was darker than the fresh juice. In all cycles, CBFC obtained higher bioactive compound concentration than evaporation, with values, in the last cycle, close to $610 \mathrm{mg} \mathrm{GAE} / 100 \mathrm{~mL}, 57 \mathrm{mg} \mathrm{M} 3 \mathrm{G} / 100 \mathrm{~mL}$ and $279 \mathrm{mg} \mathrm{CEQ} / 100 \mathrm{~mL}$ for total polyphenol, anthocyanin and flavonoid content, respectively, causing a retention over $70 \%$. Similarly, as the cycles progressed, DPPH assay presented values from 1916 to $5700 \mu \mathrm{mol}$ Trolox equivalents/L, which were higher than those reported by the treatment at high temperatures (1916 to $4600 \mu \mathrm{mol}$ Trolox equivalents/L), resulting in good antioxidant activity in the cryoconcentrates achieved at low temperatures. Moreover, a significant correlations between CIELab parameters, bioactive compounds and antioxidant activity were observed. Thus, CBFC is an interesting and novel technique to preserve important quality properties from fresh fruit juices.
\end{abstract}

Keywords: concentration; fruit juice; physicochemical properties; bioactive compounds; antioxidant activity.

Practical Application: Novel techniques are being developed to retain various bioactive components from natural fresh juices. Hence, block freeze concentration is a fascinating nonthermal technology to produce liquid concentrates. In this work, blueberry juice was concentrated by freeze concentration, obtaining interesting quality property results when compared with concentrates by the most used thermal technology, i.e., evaporation.

\section{Introduction}

In general terms, the concentration process is an important unit operation due to reduce several production costs such as storage, transportation, packaging and distribution costs, since concentrated samples occupy less volume and weight, as well as increased product foods' shelf-life. Specifically, this process can be achieved through three mechanisms: thermal treatment (evaporation), membrane technology (reverse osmosis) and freeze concentration (subzero technology) (Orellana-Palma et al., 2019).

The evaporation is the most widely used technology to concentrate fruit juice samples, in which water is vaporized with steam in a heat exchanger by applying temperatures between 50 and $150^{\circ} \mathrm{C}$. However, the high temperatures applied produce undesirable effects in the final food products due to the degradation of important components, and leads to consumer dissatisfaction. Furthermore, it has some disadvantageous such as high amount of energy to remove water $(2260 \mathrm{~kJ} / \mathrm{kg})$, high installation and operating costs, and long processing time (Ling et al., 2015). Various studies have shown the negative evaporation effects in thermolabile and thermostable components applied to pomegranate, black mulberry, sour cherry and blueberry juices (Dincer et al., 2016; Elik et al., 2016; Sabanci \& Icier, 2017).
Thereby, innovative food processing technologies have been developed to preserve different quality properties in the final concentrate juice (Khan et al., 2018).

The freeze concentration (FC) (also called cryoconcentration) is a concentration technology in continuous development, which allows concentrate a liquid solution via partial or total water freezing and separating the ice fraction from the unfrozen liquid fraction (cryoconcentrate). Thus, FC process has reached concentration levels between 30 and $60^{\circ} \mathrm{Brix}$, without affecting different quality properties in the final cryoconcentrate due to the concentration process occurs at subzero temperatures (Amran et al., 2016). Hence, different FC processes are available today: (i) suspension FC (SFC) (Ding et al., 2019), (ii) progressive FC (PFC) (Muñoz et al., 2019), (iii) falling-film FC (FFFC) (Moreno et al., 2015) and (iv) block FC (BFC) (Jin et al., 2017). In $\mathrm{BFC}$, the aqueous solution is completely freezing; thawing that frozen solution, and later, the unfrozen liquid fraction (cryoconcentrate) is separated from the ice fraction by natural gravitational method or by adding external forces to improve the separation efficiency and other process parameters. Then, BFC utilizes three steps: freezing, thawing and separation (Orellana-Palma et al., 2017a).

${ }^{1}$ Departamento de Ingeniería en Alimentos, Universidad del Bío-Bío, Chillán, Chile

${ }^{2}$ Departamento de Biotecnología, Universidad Tecnológica Metropolitana, Santiago, Chile

*Corresponding author: gpetzold@ubiobio.cl 
In this context, centrifugation has been used as powerful external force in the BFC process to extract cryoconcentrate from diverse frozen liquid samples such as brackish water (Luo et al., 2010), proteins (Virgen-Ortíz et al., 2012), extracts (Nunes et al., 2015; Sequera et al., 2019), and fruit juices (Petzold et al., 2016), since the centrifugal force uses the veins formed in the frozen fraction to extract solute and thus, this assisted technique increases the efficiency and final amount of cryoconcentrate. In consequence, centrifugal block freeze concentration (CBFC) studies have successfully reported that process parameters were improved with efficiencies between $60 \%$ and $75 \%$ applying up to three cycles (Orellana-Palma et al., 2019).

However, to our best knowledge, there is no scientific literature on $\mathrm{CBFC}$ and evaporation as technologies to concentrate fresh blueberry juice and their effects on different components, which in turn could be essential information to produce juices with important quality properties.

Thus, the aim of the present study was to analyze the effect of CBFC on physicochemical properties (total solid content, $\mathrm{pH}$, acidity and color), bioactive compounds (total polyphenol, anthocyanin and flavonoid content) and antioxidant activity (DPPH) applied to fresh blueberry juice compared with conventional high temperature treatment, i.e., evaporation method.

\section{Materials and methods}

\subsection{Chemicals and reagents}

Analytical standards: sodium hydroxide $(\mathrm{NaOH})$, sodium carbonate $\left(\mathrm{Na}_{2} \mathrm{CO}_{3}\right)$, sodium nitrite $\left(\mathrm{NaNO}_{2}\right)$, aluminum chloride $\left(\mathrm{AlCl}_{3}\right)$, hydrochloric acid $(\mathrm{HCl})$, potassium chloride $(\mathrm{KCl})$, acetic acid $\left(\mathrm{CH}_{3} \mathrm{CO}_{2} \mathrm{H}\right)$, sodium acetate $\left(\mathrm{CH}_{3} \mathrm{COONa}\right)$, Folin-Ciocalteu reagent, gallic acid, (+)-catechin, methanol, DPPH (2,2' -diphenyl-1-picrylhydrazyl) and Trolox (6-hydroxy-2,5,7,8-tetramethylchroman-2-carboxylic acid) were purchased from Sigma-Aldrich, Santiago, Chile. Distilled water was used throughout.

\subsection{Juice preparation}

Fresh blueberries (Vaccinium myrtillus L.) were purchased in the same local market in Chillán (Región del Nuble, Chile) and were stored under refrigeration condition $\left(\approx 4^{\circ} \mathrm{C}\right.$, overnight) until use. The fruits were cleaned and washed manually to remove debris. Then, blueberries were crushed manually and filtered to separate the seeds and skin from the juice, avoid the presence of solids that might interfere with the concentration processes.

\subsection{Concentration procedures}

\section{Centrifugal block freeze concentration}

The CBFC experimental protocol was adapted according to the methodology of Orellana-Palma et al. (2017a) with some modifications. A schematic diagram of the experimental protocol is illustrated in Figure 1.

Blueberry juice $(45 \mathrm{~mL})$ into plastic centrifugal tubes (internal diameter $\approx 22 \mathrm{~mm}$ ) was frozen in a static freezer at $-20{ }^{\circ} \mathrm{C}$ for $12 \mathrm{~h}$. The centrifugal tubes were isolated with foam polystyrene $(8 \mathrm{~mm}$ thickness, thermal conductivity $\mathrm{K}=0.035 \mathrm{~W} / \mathrm{mK}$ ) in order for freezing front propagation to occur axially (from the top to bottom). The freezing temperature was measured using a type $\mathrm{T}$ copper thermocouple at the geometric center of the samples, and the freezing rate $(\mu \mathrm{m} / \mathrm{s})$ was calculated as the distance divided by the freezing time (based on the ice propagation rate) (Petzold et al., 2015).

The frozen samples were transferred to a centrifuge with a $50 \mathrm{~mL}$-tube rotor (Hettich D-7853, Tuttlingen, Germany) at $20^{\circ} \mathrm{C}$ for $15 \mathrm{~min}$ at $4000 \mathrm{rpm}$ (1600 RCF) to force the separation of cryoconcentrated fraction $\left(\mathrm{C}_{\mathrm{s}}\right)$ from the ice fraction $\left(\mathrm{C}_{\mathrm{f}}\right)$. The $\mathrm{C}_{\mathrm{s}}$ at the first cycle was collected and used for the second cycle (i.e. the $\mathrm{C}_{\mathrm{s}}$ was frozen and transferred to a centrifuge), and so, the second $\mathrm{C}_{\mathrm{s}}$ was used for the third cycle. Three replicates of the CBFC experimental protocol were performed, and the mean values of physicochemical properties, bioactive compounds content and antioxidant capacity of the $\mathrm{C}_{\mathrm{s}}$ were reported.

\section{Vacuum evaporation procedure}

The fresh juice sample was concentrated with a vacuum rotary evaporator (Rotavapor R-100, Büchi Labortechnik AG, Flawil, Switzerland) at $50{ }^{\circ} \mathrm{C}$ and 80 mbar. The concentration procedure was stopped when the total soluble solids (TSS) of the evaporate juice were similar to the CBFC sample obtained in each cycle. Three replicates of the concentration by evaporation were performed, and the mean values of physicochemical properties, bioactive compounds content and antioxidant capacity were reported.

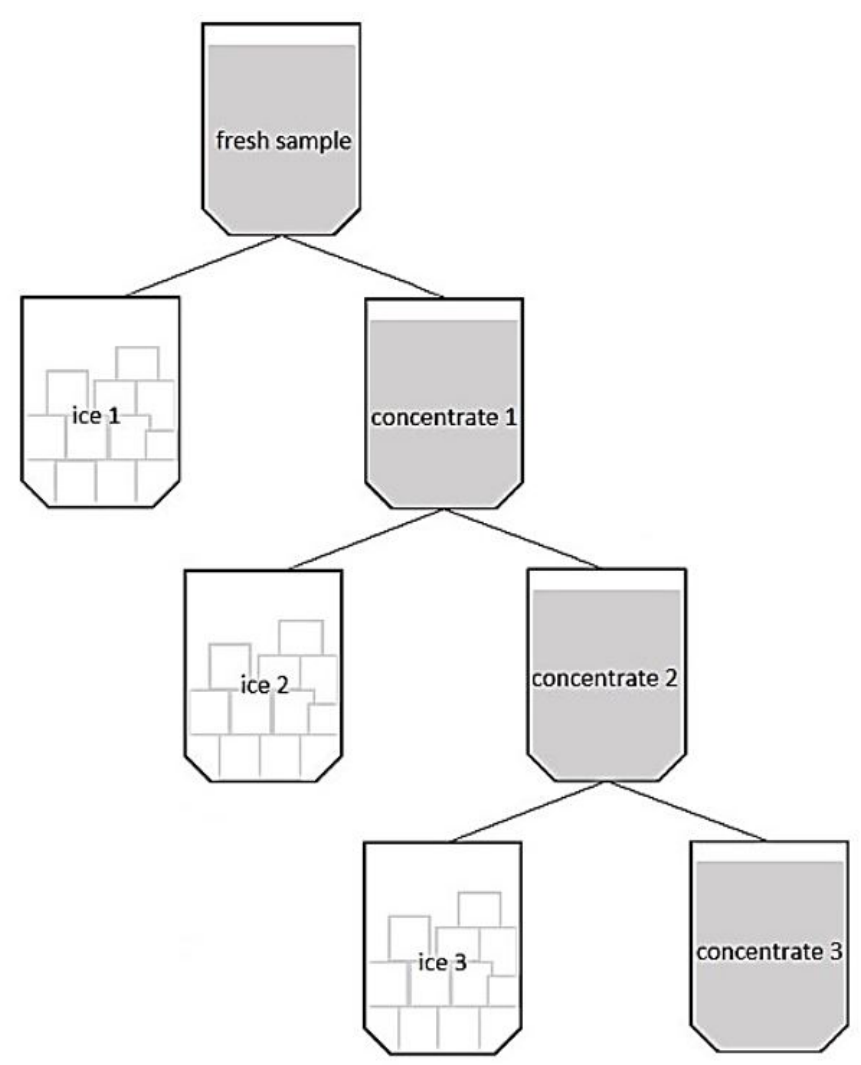

Figure 1. Centrifugal block freeze concentration using three consecutive cycles. 


\subsection{Physicochemical properties}

The TSS was analyzed using a digital refractometer PAL-1 (Atago Inc., Tokyo, Japan) and was expressed as ${ }^{\circ}$ Brix. The $\mathrm{pH}$ of fresh blueberry juice, cryoconcentrate and evaporate samples were measured using a digital pH meter (Hanna Instruments HI 2210, Woonsocket, USA) calibrated with commercial buffer solutions at $\mathrm{pH} 7.0$ and 4.0. Titratable acidity (TA) was determined by titration with $0.1 \mathrm{~N} \mathrm{NaOH}$ solution. The samples were diluted with deionized water and it was titrated to the phenolphthalein endpoint $(\mathrm{pH}=8.1 \pm 0.1)$. The titratable acidity was expressed $\mathrm{g} / 100 \mathrm{~mL}$ malic acid of the sample. The instrumental color parameters were determined using a spectrophotometer (Konica Minolta CM-5, Osaka, Japan). The results were expressed as CIELab values. The Hunter color parameters $L^{\star}$ (whiteness or brightness/darkness), $\mathrm{a}^{\star}$ (redness/greenness), and $\mathrm{b}^{\star}$ (yellowness/blueness) were used. The total color difference $\left(\Delta \mathrm{E}^{\star}\right)$ was calculated according to the Equation 1. All analyses were performed in triplicate at $25^{\circ} \mathrm{C}$.

$$
\Delta \mathrm{E}^{*}=\sqrt{(\Delta \mathrm{L})^{2}+(\Delta \mathrm{a})^{2}+(\Delta \mathrm{b})^{2}}
$$

\subsection{Total Bioactive Compounds (TBC) and antioxidant activity determinations}

Total polyphenol content (TPC) was determined spectrophotometrically by the Folin-Ciocalteu assay (Singleton et al., 1999). Gallic acid was used to prepare a calibration curve and the results were expressed as mg gallic acid equivalents (GAE) per $100 \mathrm{~mL}$ of sample (mg GAE/100 mL). Total anthocyanin content (TAC) was estimated according to the $\mathrm{pH}$ differential method as described by Lee et al. (2005). Malvidin-3-glucoside was used to prepare a calibration curve and the results were expressed as mg malvidin-3-glucoside equivalents (M3G) per $100 \mathrm{~mL}$ of sample (mg M3G/100 mL). Total flavonoid content (TFC) was measured by aluminium chloride colorimetric method described by Dewanto et al. (2002). Catequin was used to prepare a calibration curve and the results were expressed as mg catequin equivalents (CEQ) per $100 \mathrm{~mL}$ of sample (mg CEQ/100 mL). The TBC retention indicates the total bioactive compound percentage in the concentrated fraction respect to the initial sample (fresh blueberry juice). The TBC retention was calculated at each cycle using the Equation 2 (Orellana-Palma et al., 2017a).
$\operatorname{TBC}$ retention $(\%)=\left(\frac{\mathrm{C}_{0}}{\mathrm{C}_{\mathrm{T}}}\right) *\left(\frac{\mathrm{BC}_{\mathrm{T}}}{\mathrm{BC}_{0}}\right) * 100$

Where $\mathrm{C}_{0}$ is the initial TSS ( $\left.{ }^{\circ} \mathrm{Brix}\right), \mathrm{C}_{\mathrm{T}}$ is the concentration of TSS ( ${ }^{\circ}$ Brix) at each cycle, $\mathrm{BC}_{\mathrm{T}}$ is the $\mathrm{TBC}$ at each cycle, and $\mathrm{BC}_{0}$ is the initial TBC.

DPPH (2,2-diphenyl-1-picrylhydrazyl) free radical scavenging assay was assessed based on Thaipong et al. (2006)' method. Trolox was used as standard for the calibration curve, and the results were calculated and expressed as micromoles of Trolox equivalents (TE) per liter of sample ( $\mu \mathrm{mol} \mathrm{TE} / \mathrm{L}$ ). TBC and antioxidant activity determinations were performed in triplicate at $25^{\circ} \mathrm{C}$.

\subsection{Statistical analysis}

Data were analyzed using analysis of variance (ANOVA) using the Statgraphics Centurion XVI software. Differences between the mean values were established by the least significant difference (LSD) at 5\%. Correlations between color parameters, total bioactive compound and among them were evaluated by Pearson's correlation coefficient test.

\section{Results and discussion}

\subsection{Fresh blueberry juice and concentrates characterization}

Table 1 summarizes TSS, pH, TA, and color of fresh blueberry juice and concentrates. Specifically, in CBFC, the concentrate solutes increased progressively compared with the fresh sample $\left(\approx 12^{\circ} \mathrm{Brix}\right)$, with final values close to 22,33 , and $44^{\circ}$ Brix after the first, second, and third cycles, respectively. In concentration index $\left(\mathrm{CI}\right.$, ratio $\left.\mathrm{C}_{\mathrm{s}} / \mathrm{C}_{0}\right)$ terms, an increase over 1.8, 2.7 and 3.6 times was achieved from the first to the third cycle, respectively.

From a practical point of view, the cryoconcentrate results were slightly superior to those obtained previously in our laboratory with other fruit juice samples such as pineapple juice (Petzold et al., 2015) and orange juice (Orellana-Palma et al., 2017b) under comparable conditions, in which the final concentration values increased until $42^{\circ}$ Brix in the final cycle. Furthermore, the results were higher than those reported by Sánchez et al. (2010),

Table 1. Physicochemical parameters of fresh blueberry juice and concentrates.

\begin{tabular}{|c|c|c|c|c|c|c|c|}
\hline & \multirow{2}{*}{ Fresh juice } & \multicolumn{3}{|c|}{$\mathrm{CBFC}$} & \multicolumn{3}{|c|}{ Evaporation } \\
\hline & & $\mathrm{C} 1$ & $\mathrm{C} 2$ & $\mathrm{C} 3$ & $\mathrm{C} 1$ & $\mathrm{C} 2$ & C3 \\
\hline TSS & $12.3 \pm 0.1^{\mathrm{a}}$ & $22.3 \pm 1.1^{b}$ & $32.6 \pm 1.7^{c}$ & $43.9 \pm 1.6^{\mathrm{d}}$ & $23.3 \pm 1.7^{b}$ & $33.8 \pm 1.3^{c}$ & $43.6 \pm 1.6$ \\
\hline $\mathrm{pH}$ & $3.2 \pm 0.0^{\mathrm{a}}$ & $3.1 \pm 0.0^{\mathrm{b}}$ & $3.1 \pm 0.0^{c}$ & $3.0 \pm 0.0^{\mathrm{d}}$ & $3.1 \pm 0.0^{\mathrm{b}}$ & $3.1 \pm 0.0^{c}$ & $3.1 \pm 0.0^{c}$ \\
\hline $\mathrm{TA}$ & $0.6 \pm 0.0^{\mathrm{a}}$ & $1.1 \pm 0.1^{\mathrm{b}}$ & $1.5 \pm 0.1^{\mathrm{c}}$ & $2.2 \pm 0.1^{\mathrm{d}}$ & $1.3 \pm 0.1^{\mathrm{b}}$ & $1.7 \pm 0.1^{\mathrm{c}}$ & $2.3 \pm 0.1^{\circ}$ \\
\hline $\mathrm{L}^{*}$ & $1.6 \pm 0.1^{\mathrm{a}}$ & $0.9 \pm 0.0^{\mathrm{b}}$ & $0.5 \pm 0.0^{c}$ & $0.3 \pm 0.0^{\mathrm{d}}$ & $0.8 \pm 0.0^{\mathrm{b}}$ & $0.4 \pm 0.0^{c}$ & $0.3 \pm 0.0^{c}$ \\
\hline$a^{*}$ & $9.6 \pm 0.3^{\mathrm{a}}$ & $5.1 \pm 0.2^{\mathrm{b}}$ & $2.0 \pm 0.1^{\mathrm{c}}$ & $1.0 \pm 0.0^{\mathrm{d}}$ & $3.7 \pm 0.1^{b}$ & $1.3 \pm 0.1^{\mathrm{c}}$ & $0.6 \pm 0.0^{c}$ \\
\hline $\mathrm{b}^{*}$ & $2.4 \pm 0.1^{\mathrm{a}}$ & $1.2 \pm 0.0^{\mathrm{b}}$ & $0.5 \pm 0.0^{c}$ & $0.2 \pm 0.0^{\mathrm{d}}$ & $1.2 \pm 0.0^{\mathrm{b}}$ & $0.3 \pm 0.0^{c}$ & $0.2 \pm 0.0^{c}$ \\
\hline$\Delta \mathrm{E}^{*}$ & - & $4.7 \pm 0.3^{\mathrm{a}}$ & $7.9 \pm 0.3^{b}$ & $8.9 \pm 0.3^{c}$ & $6.1 \pm 0.2^{\mathrm{a}}$ & $8.6 \pm 0.3^{\mathrm{b}}$ & $9.3 \pm 0.3^{c}$ \\
\hline
\end{tabular}

${ }_{\text {a,b,c, }, \mathrm{d}}$ Different letters in the same column show significant differences at 5\% between homogeneous groups in each variable to a least significant difference test (LSD). C1, C2 and C3 represents cycle 1 , cycle 2 and cycle 3 , respectively; $\mathrm{a}^{*}$ corresponded to the green-red axis, where the negative values are related to the green color and the positive values with the orange and red; $\mathrm{b}^{*}$ corresponded to the blue-yellow axis, where the negative values are related to the color blue, and the positive values with the yellow color; $\mathrm{L}^{\star}$ coordinate measured the luminosity; $\Delta \mathrm{E}^{\star}$ corresponded to the total color difference between samples. 
Moreno et al. (2015) and Ding et al. (2019), in which orange juice, coffee extract and apple juice were cryoconcentrated by FFFC, BFC and SFC, respectively. The differences in the final solute at each cycle could be attributed to the sized tubes, since in this study, we used a $50 \mathrm{~mL}$-tube ( $45 \mathrm{~mL}$ sample) and moderate freezing temperature $\left(-20^{\circ} \mathrm{C}\right)$, which promote a better movement of the solids in the subzero step (stratification) and favors the cryoconcentrate separation from the $\mathrm{C}_{\mathrm{f}}$ Likewise, the ice occluded solutes provided values close to 3,8 and $15^{\circ} \mathrm{Brix}$ along the CBFC cycles (data not shown). Hence, the $\mathrm{C}_{\mathrm{f}}$ were highly pure at each cycle, since, in CI terms, the solutes presented a slight increase, with $0.3,0.7$ and 1.2 times at the first, second, and third cycle, respectively. The values were comparable than previous results obtained in the same study with fresh pineapple juice, where $15^{\circ}$ Brix of entrapped solutes was reached in the $\mathrm{C}_{\mathrm{f}}$ after the third cycle (Petzold et al., 2015). Similar values could be attributed to that fresh blueberry juice has no added components and/or any previous treatment carried out such as in the commercial juice production. Therefore, there are no factors that prevent a correct BFC. In the same physicochemical parameters way, the $\mathrm{pH}$ of the concentrated fractions decreased in relation to the initial fresh juice value. An opposite effect was observed in the acidity, since it increased at each cycle with respect to the initial value. This inverse behavior has been attributed to the solids concentration, since as the TSS content increases, the organic acid content in the sample increases (Khajehei et al., 2015; Orellana-Palma et al., 2019). As observed, the pH and acidity values did not present significant statistical differences $(\mathrm{p} \geq 0.05)$ when comparing the same cycles between concentration techniques. The instrumental color parameters of fresh blueberry juice and concentrates samples showed significant changes in the mean $\mathrm{L}^{\star}, \mathrm{a}^{\star}$ and $\mathrm{b}^{\star}$ values after applied concentration techniques, since all the values decreased in relation to the fresh juice, which indicated that concentrate samples were darker than the initial juice. The increase in TSS content cycle by cycle explains the darkening of the samples, which also generates the increase of bioactive compounds (Adorno et al., 2017). In addition, these results between the fresh juice and cryoconcentrate samples are in agreement with different liquid samples (Petzold et al., 2016). The color difference $\left(\Delta \mathrm{E}^{\star}\right)$ between the concentrated samples and fresh juice can be estimated such as not noticeable and well visible according to the human visual discrimination threshold $\left(\Delta E^{\star}>3\right.$ ) (Melgosa et al., 1997). From the first cycle, the $\Delta \mathrm{E}^{\star}$ values were over four CIELab units, and at each cycle increased until nine CIELab units. The $\Delta \mathrm{E}^{*}$ values acquired by evaporation were similar than those obtained by CBFC. These values confirm that $\mathrm{CBFC}$ process preserves the natural fresh juice color.

In freezing rate terms, the freezing curves (Figure 2) show a moderate freezing rate in all samples, because the results were lower than $8 \mu \mathrm{m} / \mathrm{s}$, a critical value established by Moreno et al. (2015). Specifically, the fresh juice has a freezing rate close to $5.4 \mu \mathrm{m} / \mathrm{s}$, while cryoconcentrate samples increase to values around $6.0,6.3$ and $6.6 \mu \mathrm{m} / \mathrm{s}$, from the first to the third cycle, respectively. These results were similar to the previously obtained by Petzold et al. (2015), who cryoconcentrated commercial pineapple juice. This important difference in the freezing rate and freezing curves could be attributed to the solute concentration in the fresh juice and each cycle, since as the cycles increased, the final concentration increased and the water in the juice decreased (Orellana-Palma et al., 2019).

\subsection{Bioactive compound content in the concentrated juices}

Figure 3 shows the total polyphenol (TPC), flavonoid (TFC) and anthocyanin (TAC) content of fresh blueberry juice and concentrate samples. Firstly, the fresh blueberry juice had TPC, TAC and TFC values of approximately $220 \mathrm{mg}$ GAE/100 mL (Figure 3a), $20 \mathrm{mg}$ M3G/100 mL (Figure 3b) and $110 \mathrm{mg} C E Q / 100 \mathrm{~mL}$ (Figure 3c), respectively, which was significantly higher than those previously informed by Siddiq et al. (2018). The differences with previous studies could be explained by factors such as type of harvesting, ripening stage, climatic conditions in the fresh fruits and/or specific methods used during juice preparation (Skrovankova et al., 2015). Specifically, the bioactive compound content displayed a similar behavior under $\mathrm{CFBC}$ and evaporation processes, since the results showed increased significantly $(\mathrm{p} \leq 0.05)$ over consecutive cycles when compared to the fresh blueberry juice. In all cases, the TPC, TAC and TFC values obtained by CFBC were higher than those by high temperatures, and in the final cycle, the concentrates samples exhibited values close to $610 \mathrm{mg} \mathrm{GAE} / 100 \mathrm{~mL}, 57 \mathrm{mg}$ $\mathrm{M} 3 \mathrm{G} / 100 \mathrm{~mL}$, and $279 \mathrm{mg} \mathrm{CEQ} / 100 \mathrm{~mL}$ versus $454 \mathrm{mg} \mathrm{GAE} / 100 \mathrm{~mL}$, $43 \mathrm{mg} \mathrm{M} 3 \mathrm{G} / 100 \mathrm{~mL}$, and $207 \mathrm{mg} \mathrm{CEQ} / 100 \mathrm{~mL}$, respectively. Hence, the cryoconcentrate samples presented an increased up to 3.0 (TPC), 2.9 (TAC) and 2.6 (TFC) times compared to the initial value. This tendency has been reported in yerba mate (Nunes et al., 2015), strawberry juice (Adorno et al., 2017), blueberry juice (Orellana-Palma et al., 2017a), orange juice (Orellana-Palma et al., 2017b), coffee extract (Correa et al., 2018) and apple juice (Zielinski et al., 2019).

Likewise, the TBC retention at each cycle was calculated (Figure 3, black numbers). The TBC was more than $50 \%$, but the values were significantly higher for CFBC compared with thermal method, with values over $70 \%$ and $53 \%$, respectively. Thus, for the best results (CBFC), the $\mathrm{TBC}$ retention were

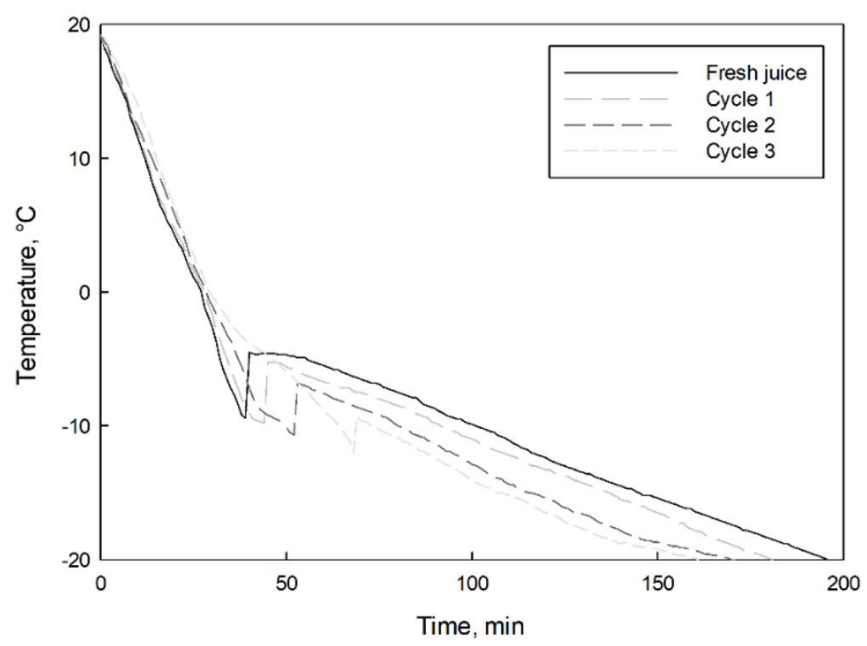

Figure 2. Freezing curves of fresh blueberry juice and cryoconcentrates at each $\mathrm{CBFC}$ cycle. 

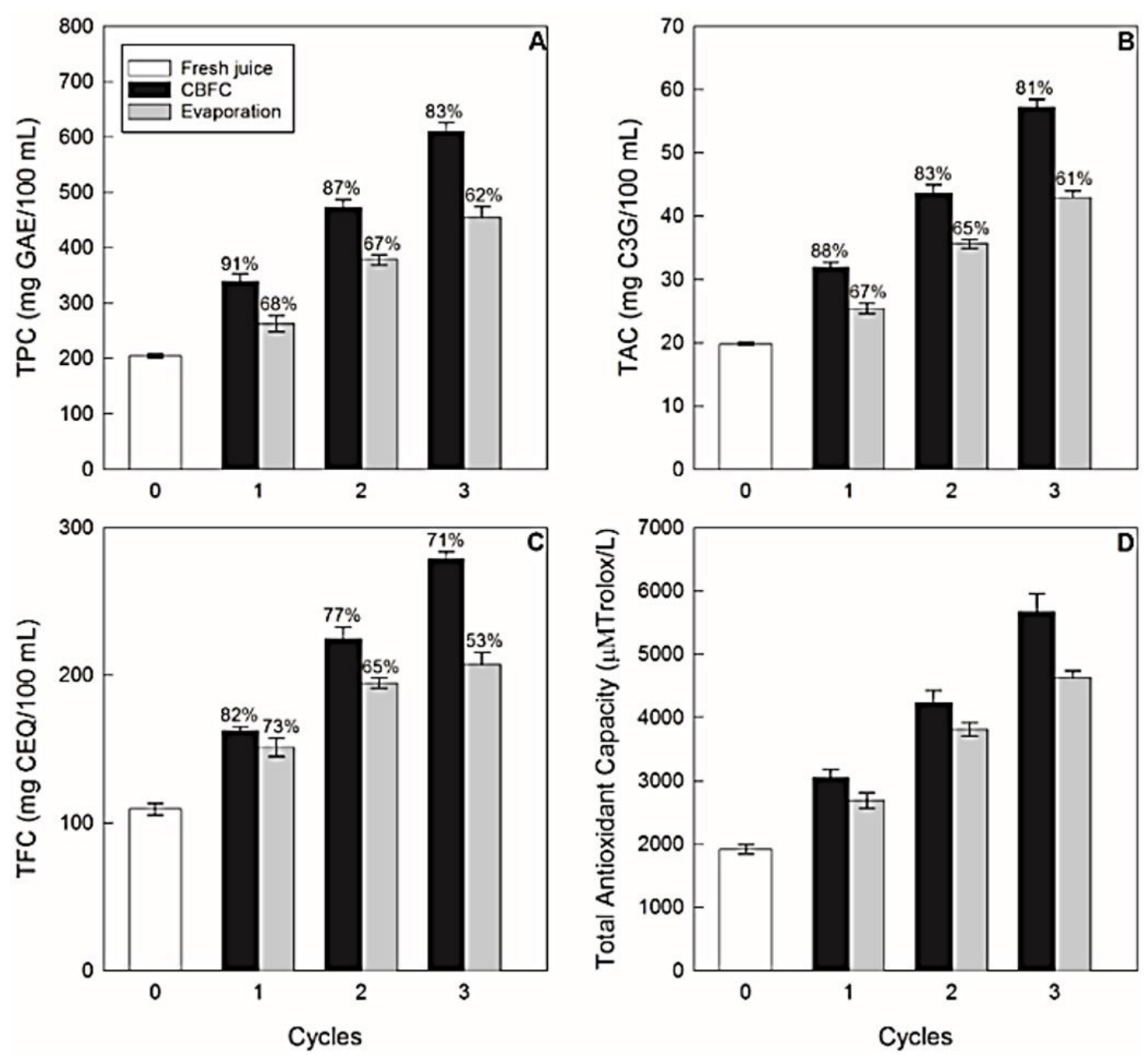

Figure 3. Total bioactive content and antioxidant activity of fresh blueberry juice and concentrates samples: (A) Polyphenols; (B) Anthocyanins; (C) Flavonoids; (D) DPPH. Numbers represent retention percentage values.

approximately $91 \%, 87 \%, 83 \%$ for TPC, $88 \%, 83 \%, 81 \%$ for TAC and $82 \%, 77 \%$ and $71 \%$ for TFC in the first, second and third cycle, respectively. The values are comparable to those reported by Orellana-Palma et al. (2017a) with CBFC in blueberry juice and Correa et al. (2018) with FFFC in aqueous coffee extract, which informed TBC retention values from $80 \%$ to $95 \%$, and $90 \%$, respectively. These high TBC retention values show the beneficial and positive effects of subzero temperatures concentration to obtain a liquid fraction rich in solutes and attractive color, and in addition, this technique allows to preserve important bioactive compounds in the final cryoconcentrate. Furthermore, the higher component values in CBFC than evaporation are attributed to the susceptibility and thermolability of bioactive compounds to the high temperatures (Petruzzi et al., 2017).

In antioxidant activity terms, the fresh blueberry juice has a value close to $1916 \mu \mathrm{mol} \mathrm{TE} / \mathrm{L}$, which was lower than previously reported by Pataro et al. (2017). The variation could be related to the growth conditions of blueberry fruits and the methodology used to obtain the fresh juice, and in turn, these influences in the anthocyanins content (main contributors in antioxidant capacity) (Skrovankova et al., 2015). The radical scavenging activity by DPPH assay showed an increased with significant differences $(\mathrm{p} \leq 0.05)$, in both CBFC and evaporation methods as the cycles progressed. In particular, CBFC presented higher values than the thermal treatment, with DPPH values of $3000 \mu \mathrm{mol} \mathrm{TE} / \mathrm{L}$ to $5700 \mu \mathrm{mol} \mathrm{TE} / \mathrm{L}$, and $2700 \mu \mathrm{mol} \mathrm{TE} / \mathrm{L}$ to $4600 \mu \mathrm{mol} \mathrm{TE} / \mathrm{L}$, from the first to the third cycle, respectively. As mentioned earlier, this behavior could be associated with the use of low temperatures in CBFC to concentrate bioactive compounds, since the damage to the sensitive components is minimal, and therefore, it process allows a higher anthocyanins concentration than the treatment at high temperatures. A similar trend was observed by Moreno et al. (2015) and Zielinski et al. (2019) during the freeze concentration of coffee extract and apple juice, respectively.

\subsection{Correlation between color parameters and bioactive compounds content}

Correlation coefficients in the last CFBC cycle for $\mathrm{L}^{*}, \mathrm{a}^{*}, \mathrm{~b}^{*}$, $\triangle \mathrm{E}^{\star}, \mathrm{TPC}, \mathrm{TAC}, \mathrm{TFC}$ and DPPH are shown in Table 2. A direct positive and significant correlation was found between the luminosity $\left(L^{*}\right)$ for $a^{*}(r=0.99)$ and $b^{*}(r=0.99)$, indicating the darkening of the samples and a reduction in the coordinates $\mathrm{a}^{*}$ and $b^{\star}$ values (see Table 1 ). However, the total color difference 
Table 2. Pearson's correlation coefficients ( $\mathrm{r}$ ) between CIELab, total bioactive compounds content and antioxidant activity obtained by CFBC process.

\begin{tabular}{cccccccc}
\hline & $\mathrm{L}^{*}$ & $\mathrm{a}^{\star}$ & $\mathrm{b}^{*}$ & $\Delta \mathrm{E}^{\star}$ & TPC & TFC & TAC \\
\hline $\mathrm{L}^{*}$ & 1.00 & & & & & & \\
$\mathrm{a}^{*}$ & $0.99^{\ddagger}$ & 1.00 & & & & \\
$\mathrm{~b}^{*}$ & $0.99^{\ddagger}$ & $0.99^{\ddagger}$ & 1.00 & & & \\
$\Delta \mathrm{E}^{\star}$ & $-0.98^{\ddagger}$ & $-0.99^{\ddagger}$ & $-0.98^{\ddagger}$ & 1.00 & & \\
TPC & $-0.95^{\ddagger}$ & $-0.96^{\ddagger}$ & $-0.96^{\ddagger}$ & $0.94^{\ddagger}$ & 1.00 & & \\
TFC & $-0.95^{\ddagger}$ & $-0.96^{\ddagger}$ & $-0.96^{\ddagger}$ & $0.95^{\ddagger}$ & $0.99^{\ddagger}$ & 1.00 & \\
TAC & $-0.94^{\ddagger}$ & $-0.95^{\ddagger}$ & $-0.96^{\ddagger}$ & $0.93^{\ddagger}$ & $0.99^{\ddagger}$ & $0.99^{\ddagger}$ & 1.00 \\
DPPH & $-0.93^{\ddagger}$ & $-0.94^{\ddagger}$ & $-0.94^{\ddagger}$ & $0.92^{\ddagger}$ & $0.99^{\ddagger}$ & $0.99^{\ddagger}$ & $0.99^{\ddagger}$ \\
\hline
\end{tabular}

'Significant at $\mathrm{p} \leq 0.05 ; \mathrm{L}^{*}$ coordinate measured the luminosity; $\mathrm{a}^{*}$ corresponded to the green-red axis, where the negative values are related to the green color and the positive values with the orange and red; $\mathrm{b}^{\star}$ corresponded to the blue-yellow axis, where the negative values are related to the color blue, and the positive values with the yellow color; $\Delta \mathrm{E}^{\star}$ corresponded to the total color difference between samples; TPC is the total polyphenol content. TFC is the total flavonoid content. TAC is the total anthocyanin content. DPPH correspond to 2,2-diphenyl-1-picrylhydrazyl free radical scavenging assay.

$\left(\Delta \mathrm{E}^{*}\right)$ was found a negative correlation for $\mathrm{L}^{*}(\mathrm{r}=-0.98)$, $a^{*}(r=-0.99)$ and $b^{*}(r=-0.98)$, which were related to decrease in the $L^{\star}, a^{*}$ and $b^{\star}$ values as the cycles progressed, and represented a significant difference between cryoconcentrated samples when compared to the fresh juice (see Table 1). CIELab values were negative and significantly correlated with bioactive compounds content and antioxidant activity, since the increase in TSS at each CBFC cycle produces inversely proportional results, i.e., as the color values decreased, the bioactive compound content (TPC, TAC and TFC) and antioxidant activity (DPPH assay) values increased. Moreover, a positive and significant correlation was observed between the bioactive compounds and DPPH assay. A similar behavior was detected to evaporation technique (see Supplementary Material Table S1). These results were also established by Correa et al. (2018), who reported correlation coefficients of 0.9 and 1.0 between antioxidant activity and bioactive compound in the freeze concentration of aqueous coffee extract.

\section{Conclusion}

$\mathrm{CBFC}$ is an effective technology to concentrate and extracting solids from an ice matrix. Precisely, the cryoconcentrate samples showed a high solute concentration (over $43^{\circ} \mathrm{Brix}$ ) and was darker than fresh juice with lower luminosity $\left(L^{*}\right)$, and the total color difference $\left(\Delta E^{\star}\right)$ showed CIELab values over 4.7 units as cycles progressed. Similarly, in the last cycle, CBFC sample obtained a high bioactive compound retention when compared to the traditional evaporation technique, reaching values close to $83 \%, 81 \%$ and $71 \%$ versus $62 \%, 61 \%$ and $53 \%$ for total polyphenol, total anthocyanin and total flavonoid content, respectively. Likewise, the DPPH assay in CBFC samples showed higher levels of antioxidant activity (3000 $\mu \mathrm{mol} \mathrm{TE} / \mathrm{L}$ to $5700 \mu \mathrm{mol} \mathrm{TE} / \mathrm{L})$ compared to evaporation samples $(2700 \mu \mathrm{mol}$ TE/L to $4600 \mu \mathrm{mol} \mathrm{TE} / \mathrm{L})$ as the cycles progressed. Therefore, the present study confirms that important quality properties are preserved using centrifugal block freeze concentration as a concentrate technique applied to fruit juices.

\section{Acknowledgements}

Nidia Casas-Forero and Patricio Orellana-Palma are grateful for the financial support provided by Doctoral Fellowship (2017) and Scholarship for Participation in National and International Events and Research (2018) through Graduate School at Universidad del Bío-Bío, and CONICYT-Chile through FONDECYT Postdoctoral Fellowship 2019 (Folio 3190420), respectively.

\section{References}

Adorno, W. T., Rezzadori, K., Arend, G. D., Chaves, V. C., Reginatto, F. H., di Luccio, M., \& Petrus, J. C. C. (2017). Enhancement of phenolic compounds content and antioxidant activity of strawberry (Fragaria $\times$ ananassa) juice by block freeze concentration technology. International Journal of Food Science \& Technology, 52(3), 781-787. http://dx.doi.org/10.1111/ijfs.13335.

Amran, N. A., Samsuri, S., Safiei, N. Z., Zakaria, Z. Y., \& Jusoh, M. (2016). Review: parametric study on the performance of progressive cryoconcentration system. Chemical Engineering Communications, 203(7), 957-975. http://dx.doi.org/10.1080/0 0986445.2015.1075982.

Correa, L. J., Ruiz, Y., \& Moreno, F. L. (2018). Effect of falling-film freeze concentration on bioactive compounds in aqueous coffee extract. Journal of Food Process Engineering, 41(1), e12606. http:// dx.doi.org/10.1111/jfpe.12606.

Dewanto, V., Wu, X., Adom, K. K., \& Liu, R. H. (2002). Thermal processing enhances the nutritional value of tomatoes by increasing total antioxidant activity. Journal of Agricultural and Food Chemistry, 50(10), 3010-3014. http://dx.doi.org/10.1021/jf0115589 PMid:11982434.

Dincer, C., Tontul, I., \& Topuz, A. (2016). A comparative study of black mulberry juice concentrates by thermal evaporation and osmotic distillation as influenced by storage. Innovative Food Science \& Emerging Technologies, 38, 57-64. http://dx.doi.org/10.1016/j. ifset.2016.09.012.

Ding, Z., Qin, F. G., Yuan, J., Huang, S., Jiang, R., \& Shao, Y. (2019). Concentration of apple juice with an intelligent freeze concentrator. Journal of Food Engineering, 256, 61-72. http://dx.doi.org/10.1016/j. jfoodeng.2019.03.018.

Elik, A., Yanık, D. K., Maskan, M., \& Göğüş, F. (2016). Influence of three different concentration techniques on evaporation rate, color and phenolics content of blueberry juice. Journal of Food Science and Technology, 53(5), 2389-2395. http://dx.doi.org/10.1007/s13197016-2213-0 PMid:27407205.

Jin, J., Yurkow, E. J., Adler, D., \& Lee, T. C. (2017). A novel approach to improve the efficiency of block freeze concentration using ice nucleation proteins with altered ice morphology. Journal of Agricultural and Food Chemistry, 65(11), 2373-2382. http://dx.doi.org/10.1021/ acs.jafc.6b03710 PMid:28241114. 
Khajehei, F., Niakousari, M., Eskandari, M. H., \& Sarshar, M. (2015). Production of pomegranate juice concentrate by complete block cryoconcentration process. Journal of Food Process Engineering, 38(5), 488-498. http://dx.doi.org/10.1111/jfpe.12179.

Khan, M. K., Ahmad, K., Hassan, S., Imran, M., Ahmad, N., \& Xu, C. (2018). Effect of novel technologies on polyphenols during food processing. Innovative Food Science \& Emerging Technologies, 45, 361-381. http://dx.doi.org/10.1016/j.ifset.2017.12.006.

Lee, J., Durst, R., \& Wrolstad, R. (2005). Determination of total monomeric anthocyanin pigment content of fruit juices, beverages, natural colorants, and wines by the $\mathrm{pH}$ differential method: Collaborative study. Journal of AOAC International, 88(5), 1269-1278. http:// dx.doi.org/10.1093/jaoac/88.5.1269 PMid:16385975.

Ling, B., Tang, J., Kong, F., Mitcham, E. J., \& Wang, S. (2015). Kinetics of food quality changes during thermal processing: a review. Food and Bioprocess Technology, 8(2), 343-358. http://dx.doi.org/10.1007/ s11947-014-1398-3.

Luo, C., Chen, W., \& Han, W. (2010). Experimental study on factors affecting the quality of ice crystal during the freezing concentration for the brackish water. Desalination, 260(1-3), 231-238. http://dx.doi. org/10.1016/j.desal.2010.04.018.

Melgosa, M., Hita, E., Poza, A. J., Alman, D. H., \& Berns, R. S. (1997). Suprathreshold color-difference ellipsoids for surface colors. Color Research and Application, 22(3), 148-155. http://dx.doi.org/10.1002/ (SICI) 1520-6378(199706)22:3<148::AID-COL3>3.0.CO;2-R.

Moreno, F. L., Quintanilla-Carvajal, M. X., Sotelo, L. I., Osorio, C., Raventós, M., Hernández, E., \& Ruiz, Y. (2015). Volatile compounds, sensory quality and ice morphology in falling-film and block freeze concentration of coffee extract. Journal of Food Engineering, 166, 64-71. http://dx.doi.org/10.1016/j.jfoodeng.2015.05.018.

Muñoz, I. D. B., Rubio, A., Blanco, M., Raventós, M., Hernández, E., \& Prudêncio, E. S. (2019). Progressive freeze concentration of skimmed milk in an agitated vessel: Effect of the coolant temperature and stirring rate on process performance. Food Science \& Technology International, 25(2), 150-159. http://dx.doi.org/10.1177/1082013218803263 PMid:30286622.

Nunes, G. L., Boaventura, B. C. B., Pinto, S. S., Verruck, S., Murakami, F. S., Prudêncio, E. S., \& Amboni, R. D. D. M. C. (2015). Microencapsulation of freeze concentrated ilex paraguariensis extract by spray drying. Journal of Food Engineering, 151, 60-68. http://dx.doi.org/10.1016/j. jfoodeng.2014.10.031.

Orellana-Palma, P., Petzold, G., Guerra-Valle, M., \& Astudillo-Lagos, M. (2017a). Impact of block cryoconcentration on polyphenol retention in blueberry juice. Food Bioscience, 20, 149-158. http:// dx.doi.org/10.1016/j.fbio.2017.10.006.

Orellana-Palma, P., Petzold, G., Andana, I., Torres, N., \& Cuevas, C. (2017b). Retention of ascorbic acid and solid concentration via centrifugal freeze concentration of orange juice. Journal of Food Quality, 5214909, 1-7. http://dx.doi.org/10.1155/2017/5214909.

Orellana-Palma, P., González, Y., \& Petzold, G. (2019). Improvement of centrifugal cryoconcentration by ice recovery applied to orange juice. Chemical Engineering \& Technology, 42(4), 925-931. http:// dx.doi.org/10.1002/ceat.201800639.

Pataro, G., Bobinaite, R., Bobinas, Č., Šatkauskas, S., Raudonis, R., Visockis, M., Ferrari, G., \& Viškelis, P. (2017). Improving the extraction of juice and anthocyanins from blueberry fruits and their by-products by application of pulsed electric fields. Food and
Bioprocess Technology, 10(9), 1595-1605. http://dx.doi.org/10.1007/ s11947-017-1928-x.

Petruzzi, L., Campaniello, D., Speranza, B., Corbo, M. R., Sinigaglia, M., \& Bevilacqua, A. (2017). Thermal treatments for fruit and vegetable juices and beverages: A literature overview. Comprehensive Reviews in Food Science and Food Safety, 16(4), 668-691. http://dx.doi. org/10.1111/1541-4337.12270.

Petzold, G., Moreno, J., Lastra, P., Rojas, K., \& Orellana, P. (2015). Block freeze concentration assisted by centrifugation applied to blueberry and pineapple juices. Innovative Food Science \& Emerging Technologies, 30, 192-197. http://dx.doi.org/10.1016/j.ifset.2015.03.007.

Petzold, G., Orellana, P., Moreno, J., Junod, J., \& Bugueño, G. (2016). Freeze concentration as a technique to protect valuable heat-labile components of foods. In J. J. Moreno (Ed.), Innovative processing technologies for foods with bioactive compounds (pp. 184-190). Boca Raton: CRC Press.

Sabanci, S., \& Icier, F. (2017). Applicability of ohmic heating assisted vacuum evaporation for concentration of sour cherry juice. Journal of Food Engineering, 212, 262-270. http://dx.doi.org/10.1016/j. jfoodeng.2017.06.004.

Sánchez, J., Ruiz, Y., Raventós, M., Auleda, J. M., \& Hernández, E. (2010). Progressive freeze concentration of orange juice in a pilot plant falling film. Innovative Food Science \& Emerging Technologies, 11(4), 644-651. http://dx.doi.org/10.1016/j.ifset.2010.06.006.

Sequera, S. C., Ruiz, Y., Moreno, F. L., Quintanilla-Carvajal, M. X., \& Salcedo, F. (2019). Rheological evaluation of gelation during thermal treatments in block freeze concentration of coffee extract. Journal of Food Engineering, 242, 76-83. http://dx.doi.org/10.1016/j. jfoodeng.2018.07.030.

Siddiq, M., Dolan, K. D., Perkins-Veazie, P., \& Collins, J. K. (2018). Effect of pectinolytic and cellulytic enzymes on the physical, chemical, and antioxidant properties of blueberry (Vaccinium corymbosum L.) juice. Lebensmittel-Wissenschaft + Technologie, 92, 127-132. http:// dx.doi.org/10.1016/j.lwt.2018.02.008.

Singleton, V. L., Orthofer, R., \& Lamuela-Raventos, R. M. (1999). Analysis of total phenols and other oxidation substrates and antioxidants by means of Folin-Ciocalteu reagent. Methods in Enzymology, 299, 152-178. http://dx.doi.org/10.1016/S0076-6879(99)99017-1.

Skrovankova, S., Sumczynski, D., Mlcek, J., Jurikova, T., \& Sochor, J. (2015). Bioactive compounds and antioxidant activity in different types of berries. International Journal of Molecular Sciences, 16(10), 24673-24706. http://dx.doi.org/10.3390/ijms161024673 PMid:26501271.

Thaipong, K., Boonprakob, U., Crosby, K., Cisneros-Zevallos, L., \& Byrne, D. H. (2006). Comparison of ABTS, DPPH, FRAP, and ORAC assays for estimating antioxidant activity from guava fruit extracts. Journal of Food Composition and Analysis, 19(6-7), 669-675. http:// dx.doi.org/10.1016/j.jfca.2006.01.003.

Virgen-Ortíz, J. J., Ibarra-Junquera, V., Osuna-Castro, J. A., EscalanteMinakata, P., Mancilla-Margalli, N. A., \& Ornelas-Paz, J. D. J. (2012). Method to concentrate protein solutions based on dialysis-freezingcentrifugation: Enzyme applications. Analytical Biochemistry, 426(1), 4-12. http://dx.doi.org/10.1016/j.ab.2012.03.019 PMid:22475503.

Zielinski, A. A., Zardo, D. M., Alberti, A., Bortolini, D. G., Benvenutti, L., Demiate, I. M., \& Nogueira, A. (2019). Effect of cryoconcentration process on phenolic compounds and antioxidant activity in apple juice. Journal of the Science of Food and Agriculture, 99(6), 2786-2792. http://dx.doi.org/10.1002/jsfa.9486 PMid:30430576. 


\section{Supplementary Material}

Supplementary material accompanies this paper.

Table S1. Pearson's correlation coefficients ( $r$ ) between CIELab, total bioactive compounds content and antioxidant activity obtained by evaporation process.

This material is available as part of the online article from http://www.scielo.br/cta 